\title{
Impact of Autologous and Allogeneic Stem Cell Transplantation in Peripheral T-Cell Lymphomas
}

\author{
Peter Reimer \\ Klinik für Hämatologie, Internistische Onkologie und Stammzelltransplantation, Kliniken Essen Süd, \\ Evangelisches Krankenhaus Essen-Werden gGmbH, Pattbergstraße 1-3, 45239 Essen, Germany \\ Correspondence should be addressed to Peter Reimer, p.reimer@kliniken-essen-sued.de
}

Received 25 August 2010; Revised 12 October 2010; Accepted 18 October 2010

Academic Editor: Brian Bolwell

Copyright ( $\odot 2010$ Peter Reimer. This is an open access article distributed under the Creative Commons Attribution License, which permits unrestricted use, distribution, and reproduction in any medium, provided the original work is properly cited.

Peripheral T/NK-cell lymphomas (PTCLs) are rare malignancies characterized by poor prognosis. So far, no standard therapy has been established, due to the lack of randomised studies. High-dose therapy and autologous stem cell transplantation (HDTautoSCT) have shown good feasibility with low toxicity in retrospective studies. In relapsing and refractory PTCL several comparison analyses suggest similar efficacy for PTCL when compared with aggressive B-cell lymphoma. In the upfront setting, prospective data show promising results with a long-lasting overall survival in a relevant subset of patients. Achieving a complete remission at transplantation seems to be the most important prognostic factor. Allogeneic stem cell transplantation (alloSCT) has been investigated only as salvage treatment. Especially when using reduced intensity conditioning regimen, eligible patients seem to benefit from this approach. To define the role for upfront stem cell transplantation a randomised trial by the German High-Grade Non-Hodgkin Lymphoma Study Group comparing HDT-autoSCT and alloSCT will be initiated this year.

\section{Introduction}

Peripheral T-cell lymphomas (PTCLs) represent approximately $10 \%-15 \%$ of all non-Hodgkin's lymphomas (NHLs) in Western countries [1-3]. Although the clinical appearance and the manifestation sites vary widely between the different subgroups, most PTCL share some characteristics. Most patients are of older age (median age $>60$ years) and usually present with advanced stage disease $[4,5]$. PTCLs in general show an aggressive course and most studies detect the Tcell phenotype as an independent negative prognostic factor [6-9]. Both, the international prognostic index (IPI) and the prognostic index for T-cell lymphomas (PITs) that also include the bone marrow involvement, have shown prognostic value in PTCL and determine the outcome of patients with nodal PTCL [10-13]. In addition, in retrospective studies further parameters like the expression of Ki-67, the level of $\beta_{2}$-microglobulin, and the detection of the EpsteinBarr virus (EBV) have been found to have some prognostic relevance in PTCL [14-16].
The prognosis of PTCL is poor with the exception of the ALK (anaplastic lymphoma kinase) expressing anaplastic large cell lymphoma (ALCL) with a more favourable outcome after conventional chemotherapy and the primary cutaneous T-cell lymphomas (CTCL) that usually show an indolent clinical course $[17,18]$. In contrast, for the remaining PTCL the outcome following anthracycline-based chemotherapy is worse compared to aggressive B-cell lymphomas even regarding the pre-rituximab era with a median overall survival (OS) of 9 to 42 months [19-21].

So far, no accepted standard treatment could be defined for PTCL. This mainly results from a lack of PTCLrestricted randomised trials and the heterogeneity of most published series. Although the CHOP (cyclophosphamide, doxorubicin, vincristine, and prednisone) and CHOP-like regimen are widely used first-line, these protocols have never been established prospectively in PTCL and are rather adopted from treatment strategies for aggressive B-cell lymphomas. Even the role of anthracyclines in the first-line treatment of PTCL is controversial since a large retrospective 
international survey did not reveal a significant impact on OS [5].

To improve the treatment results in PTCL more aggressive strategies such as high-dose therapy with autologous stem cell transplantation (HDT-autoSCT) and allogeneic stem cell transplantation (alloSCT) seem attractive strategies in PTCL. In this paper the data on stem cell transplantation for PTCL will be discussed.

\section{Autologous Stem Cell Transplantation}

2.1. Second-Line Therapy. HDT-autoSCT has become the standard of care in relapsing and primary refractory highgrade B-cell lymphomas. In PTCL, prospective randomized studies on salvage HDT-autoSCT are lacking. To date, at least 16 retrospective studies, each including more than 15 patients have addressed this issue and are listed in Table 1 [22-37].

The cited studies were heterogeneous in terms of histological subgroups, patient characteristics, prognostic factors, myeloablative regimen, and duration of followup. In addition, some series included patients receiving upfront autoSCT and did not provide separate analyses for the patients treated in second line. Taken together, this strategy is feasible and safe with a low morbidity and mortality rate. The OS in these series ranged from 35\% at 2 years to $70 \%$ at 5 years, respectively, and the diseasefree survival (DFS) or event-free survival (EFS) from $28 \%$ at 2 years to $56 \%$ at 5 years, respectively. Although the earlier reports tend to show somewhat better results than the series published recently, when subgroup or matched control analyses were performed, the OS results for PTCL were equivalent to the long-term outcome in patients with aggressive B-cell lymphomas [22, 26, 32]. So far, it is unclear whether histology impacts the outcome of PTCL after salvage autoSCT. In some series ALCL showed a favorable outcome compared to other pathological subtypes [25, 26, 30, 31]. However, the ALK status was not determined in all series and furthermore, Zamkoff et al. could not demonstrate a long-term DFS for recurrent (ALK-negative) ALCL following HDT-autoSCT [29]. The encouraging results for patients with ALCL by Fanin et al., (5-year OS and PFS of $70 \%$ and $56 \%$, resp.) were probably biased by age and inclusion of patients in first complete remission (CR), who showed a significantly better outcome in a subgroup analysis [23].

The disease status at the time of transplantation often correlates with the outcome after salvage HDT-autoSCT. In fact, several authors found a better long-term survival in patients transplanted in CR than in patients with other disease status at transplantation [23, 27, 32, 33, 35-37]. Other authors could not confirm this finding in their survey $[24,25,31]$. However, since all data in this setting are generated retrospectively, the value of this observation needs further observation.

In summary, second-line HDT-autoSCT in PTCL is feasible and seems an effective approach for a considerable subgroup of patients.
2.2. First-Line Therapy. Some retrospective studies on upfront HDT-autoSCT have been published and are summarized in Table 2(a) [38-43]. Like in the salvage setting, a comparison of the cited series is hampered by their variety. Some series reported mainly on patients with a low or intermediate low IPI, whereas others predominantly included patients with an unfavorable prognostic index. In addition, most studies contained patients receiving HDTautoSCT in second line, but not all of them show a subgroup analysis for the upfront setting. The OS in these retrospective studies ranged from $53 \%$ at 3 years to $62-68 \%$ at 5 years. Interestingly, the DFS/EFS did not appear to be much lower than the OS in most cohorts that might indicate a substantial curative potential for this approach in previously untreated PTCL. The EBMT (European Group for Blood and Marrow Transplantation) published the largest study in this setting. Kyriakou et al reported data on 146 patients with angioimmunoblastic T-cell lymphoma (AITL) showing an actuarial OS of $67 \%$ at 2 years and $59 \%$ at 4 years, respectively, after a median observation of 31 months. About two thirds of the patients were transplanted in first CR or PR. Interestingly, patients who received a TBI- (total body irradiation-) based conditioning regimen had a significantly lower relapse rate in this study [41].

In these retrospective studies chemotherapy-sensitive disease was the major factor predicting OS and PFS [3941, 43]. Patients transplanted in CR or PR showed a superior long-term outcome compared to patients with chemotherapy-refractory disease. Other parameters (e.g., age, PIT, IPI) could not consistently be detected as being of prognostic value.

Although mainly showing promising results, the cited retrospective studies are limited by focussing on patients, only, who actually proceed to transplantation leading to superior results due to patient selection.

Prospective randomized PTCL-restricted studies assessing the value of upfront high-dose therapy in PTCL are lacking. Two French trials by the GELA (Groupe d'Etude des Lymphomes de l'Adulte) published data on autoSCT as frontline strategy in poor-risk, aggressive NHL, including PTCL [57-59]. In the LNH87-2 study, patients were treated with either consolidative sequential chemotherapy or HDTautoSCT $[57,58]$. The LNH93-3 trial compared a high-dose arm with shortened first-line myeloablative chemotherapy with a sequential consolidation chemotherapy arm. In the intent-to-treat analysis, none of these studies demonstrated a significant benefit for the high-dose arm [59]. In addition, a pooled data matched control analysis failed to show a significant advantage for upfront $\operatorname{HDT}$-autoSCT $[44,60]$. However, the limited number of patients in the highdose group and the restriction to high-risk patients, only, do not allow to definitely clarify the impact of firstline HDT-autoSCT in PTCL from these data. In another subgroup analysis, Nickelsen et al. reported results of 33 patients with PTCL from a single-arm study by the German High-Grade Non-Hodgkin Lymphoma Study Group [45]. Patients with high-risk aggressive lymphomas were treated with dose-escalated CHOP plus etoposide necessitating repeated autoSCT. Compared to B-cell NHL, PTCL showed a 


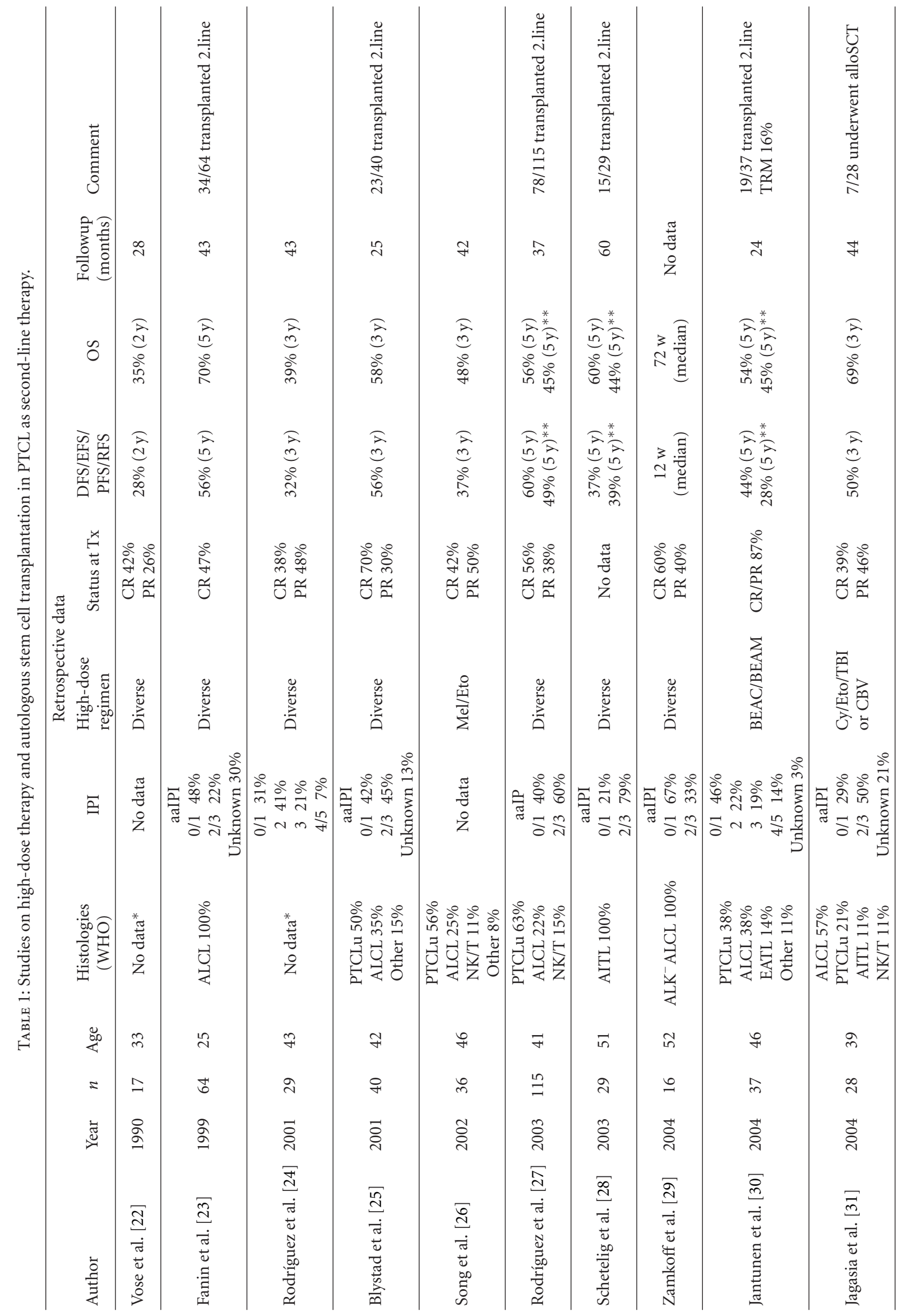




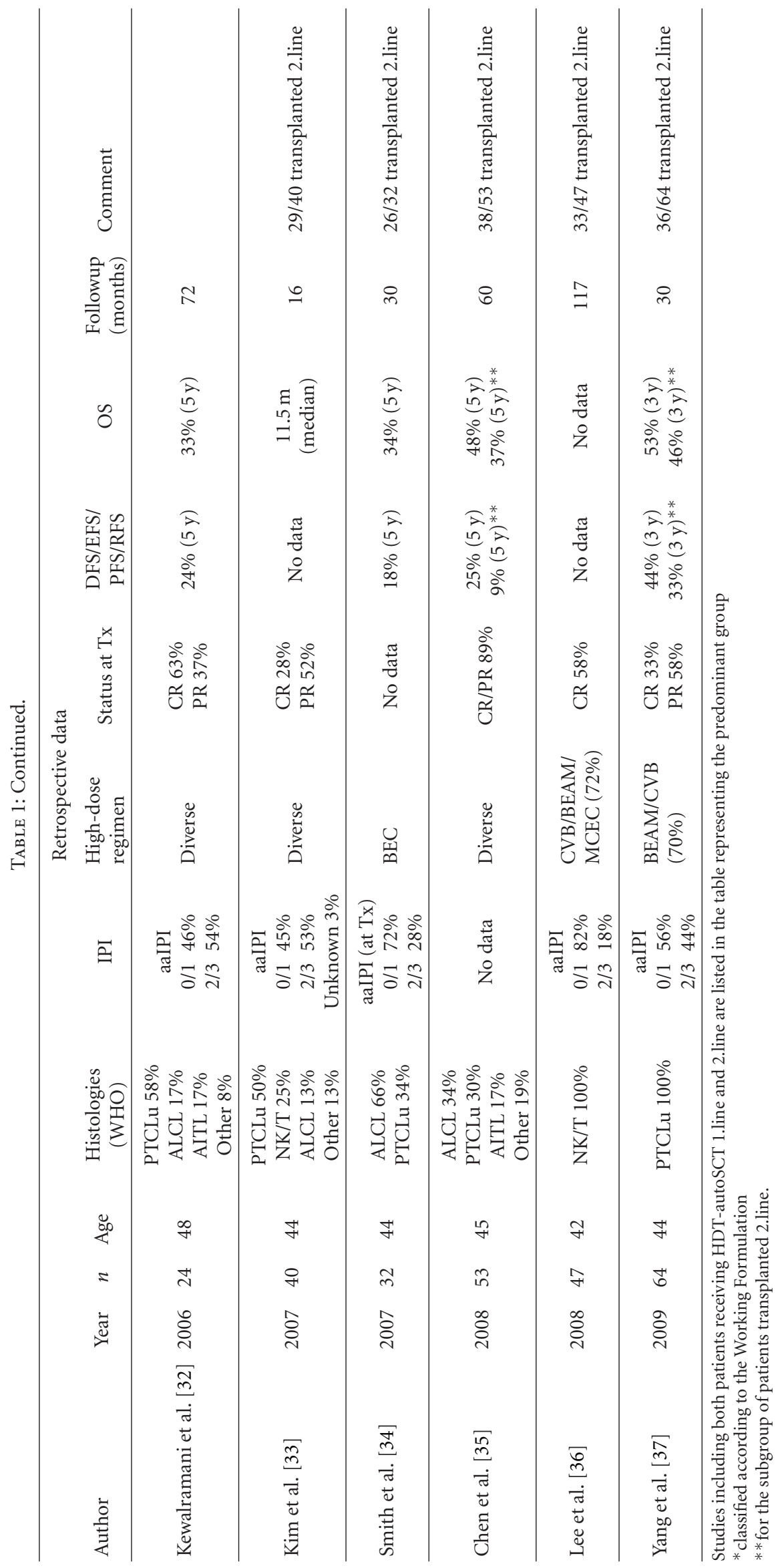




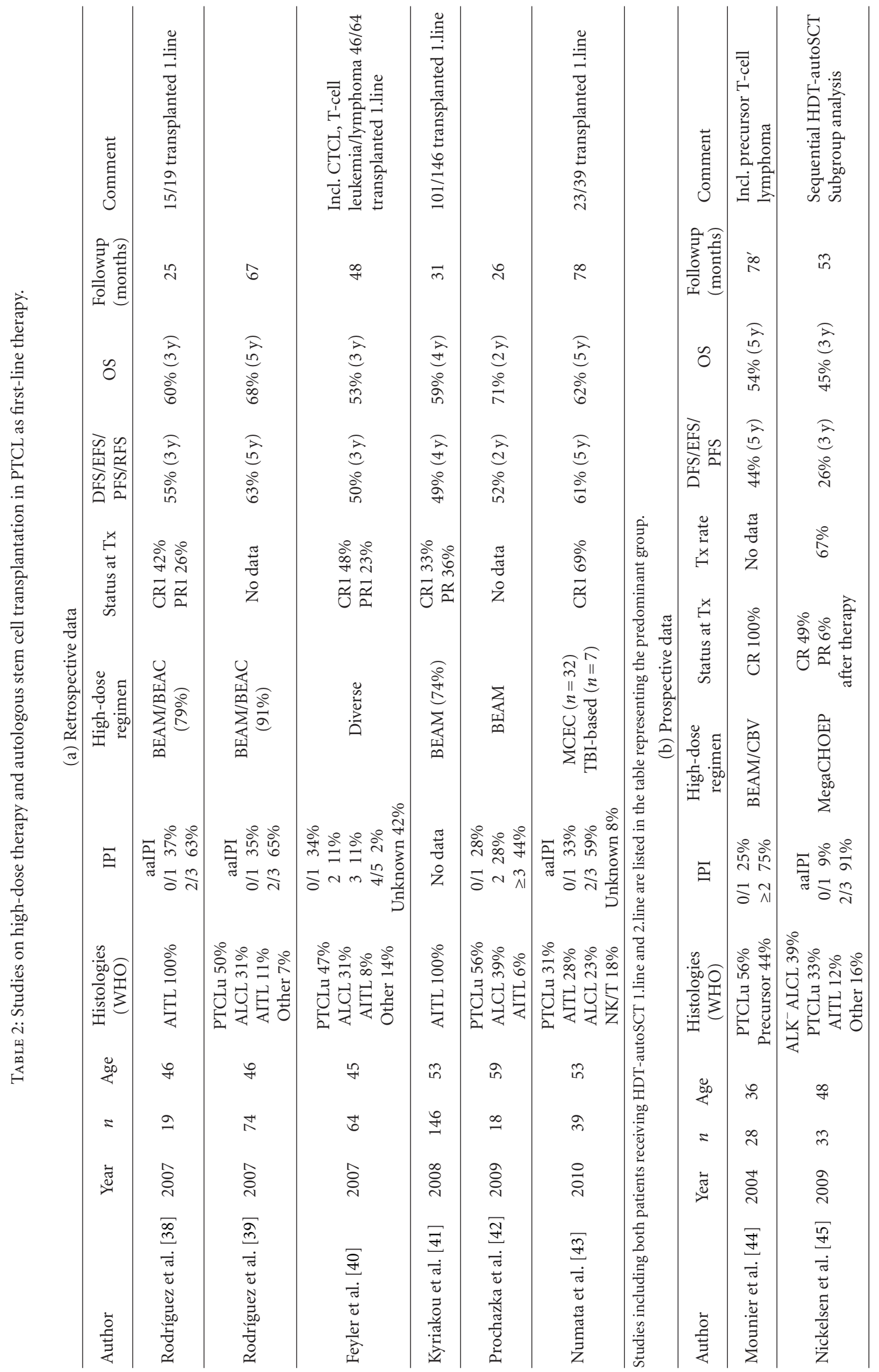




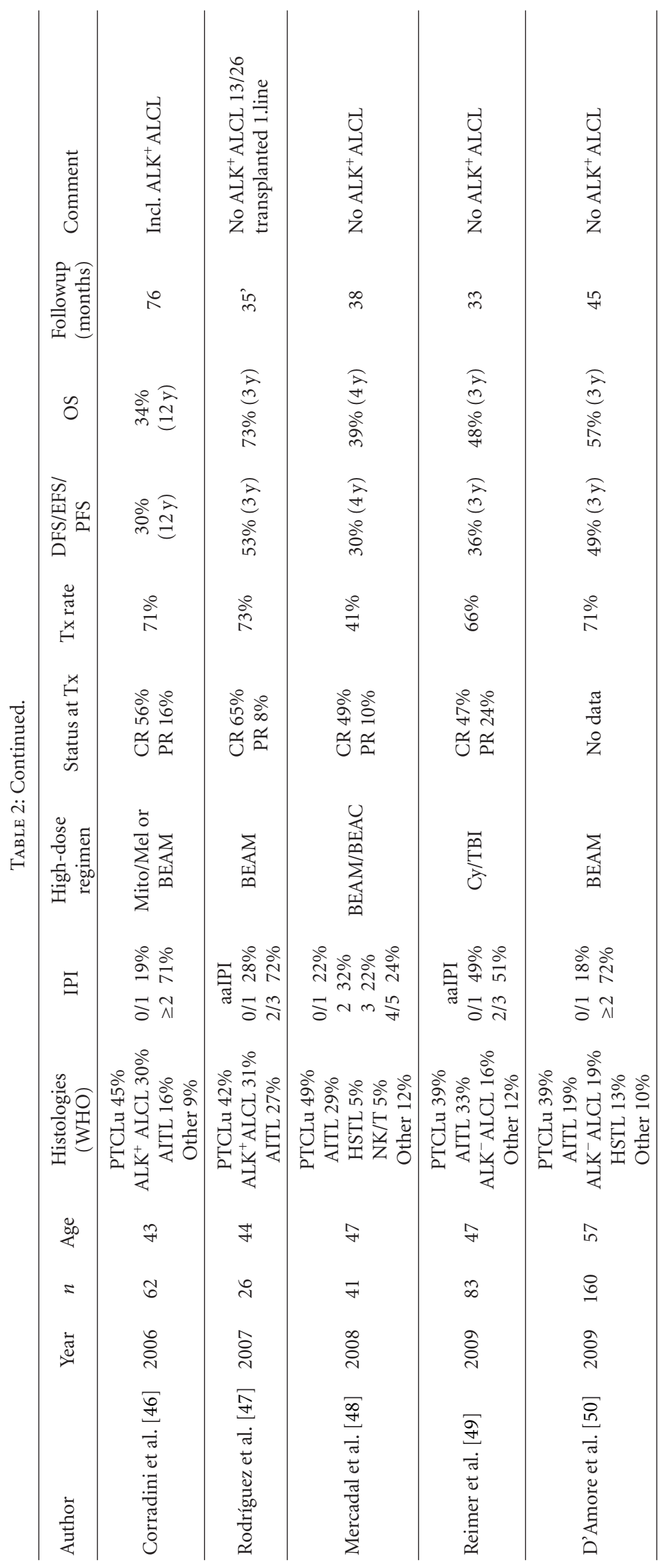


significantly worse OS and EFS at 3 years in an intent-to-treat analysis.

So far, five larger prospective PTCL-restricted trials have published data on 372 patients with frontline HDT-autoSCT [46-50]. Compared to the cited retrospective studies, these prospective series are much more homogeneous. The median age ranged between 43 and 57 years, PTCL unspecified; AITL and ALCL accounted for 77 to $100 \%$ of all histological subtypes; the age-adjusted IPI was high or intermediate high in 46 to $72 \%$; the most commonly used myeloablative regimen was the BEAM protocol $(n=228)$, and the disease status at transplantation was CR or PR in 59 to $76 \%$. Only one study included ALK-positive ALCL [46]. In these trials the OS ranged from 48 to $73 \%$ at 3 years to $34 \%$ at 12 years. The DFS/EFS or the progression-free survival (PFS) was between 36 to $53 \%$ at 3 years and $30 \%$ at 12 years. One consistently found problem of upfront HDT-autoSCT is early progressive disease leading to about one third of patients in intent-to-treat analyses, who finally fail to achieve transplantation. Mercadal et al. reported a still significant lower transplantation rate of $41 \%$. Of note, in this trial poor stem cell mobilization was the second most frequent cause of failing HDT-autoSCT [48].

With regard to these prospective data, again the remission status at the time of transplantation was a significantly prognostic factor in most studies that provided this analysis [46-48]. In addition, the IPI and PIT also show prognostic value in some [48, 49] but not in all series [47]. Other parameters, for example, histological subtype, age, sex, stage have not been concordantly been found to impact the outcome. The prospective series on upfront autoSCT are listed in Table 2(b).

\section{Allogeneic Stem Cell Transplantation}

In contrast to the cytotoxic effect of HDT-autoSCT, allogeneic SCT (alloSCT) could add a graft-versus-lymphoma (GVL) effect to the myeloablative or reduced intensity conditioning (RIC) regimen, potentially improving the therapeutic outcome. However, the experience with alloSCT for PTCL is limited. To date, no relevant data for the upfront setting are available. Besides some case reports, five retrospective series with at least 10 patients have been reported in patients with relapsing and refractory PTCL (Table 3(a)) [40, 51-54].

The largest series was published by the Société Française de Greffe de Moëlle et de Thérapie Cellulaire. In 77 pretreated patients who mainly had a myeloablative conditioning regimen the 5-year OS and PFS were 57\% and 53\%, respectively, after a median followup of 43 months. The treatment-related mortality (TRM) was $33 \%$ at 5 years. In a multivariate analysis, chemotherapy-resistant disease at transplantation and grade $3 / 4$ acute graft-versus-host disease (GVHD) were the strongest adverse prognostic factors for OS. The TRM was similar in both conditioning groups [53]. Most studies could reveal a GVL effect [52-54]. However, the TRM/NRM (nonrelapse mortality) had a relevant impact on outcome and was increasing over time up to $69 \%$ at 3 years in the series by Hamadani et al [52]. The OS ranged from $40 \%$ at 2 years to $57 \%$ at 5 years.

Two prospective studies have been published so far (Table 3(b)) $[55,56]$. In the Italian phase II trial by Corradini et al. 17 patients underwent RIC and alloSCT as salvage therapy [55]. Eight out of 17 patients had failed front-line HDT-autoSCT. After a median followup of 28 months, 14 of 17 patients were alive. The estimated 3 -year OS and PFS rates were $81 \%$ and $64 \%$, respectively. The TRM was impressively low with only $6 \%$. Notably, donor lymphocyte infusions given at the time of progression resulted in a disease response in two out of four patients, indicating evidence of a GVL effect. In the German study by Wulf et al. 10 patients were treated with chemotherapy combined with the humanized antiCD52 monoclonal antibody, alemtuzumab, followed by RIC and alloSCT. Two patients had prior HDT-autoSCT. The OS was 70\% with six patients in CR after a median followup of 7 months [56].

\section{Summary}

Due to their generally poor prognosis after conventional chemotherapy more effective treatment strategies in PTCL are urgently needed. Although randomised trials are lacking, HDT-autoSCT can be regarded as feasible and safe in PTCL. In the salvage setting, several subgroup analysis and comparisons show similar results compared to diffuse large-cell B-cell lymphoma. This finding could recently be confirmed by Sohn et al. [61]. Therefore, taken together the existing data, HDT-autoSCT seems a reasonable approach in relapsing and refractory PTCL particularly in those with chemotherapy-sensitive disease.

The value of upfront HDT-autoSCT remains to be definitely established. A recently published retrospective comparison did not find a significant benefit of this strategy compared to conventional treatment [62]. However, in this study the high-dose group was heterogeneous ranging from high-dose CHOP to alloSCT. In contrast, other retrospective studies revealed a significant better outcome when HDTautoSCT was compared to chemotherapy, alone $[5,36]$. Taken together, the prospective data mainly show promising results, especially for patients achieving a good remission status prior to transplantation, that has been reported as independent prognostic factor in most series. Therefore, these patients should mainly be regarded as candidates for upfront autoSCT. Since one major obstacle of this approach is early progressive disease, novel treatment concepts incorporating new agents and/or dose-dense regimen should be further investigated to improve remission status prior to transplantation. In a subanalysis of several trials by the DSHNHL (German High-Grade Non-Hodgkin Lymphoma Study Group), the addition of etoposide to the CHOPprotocol improved the outcome in younger patients with PTCL [63]. Furthermore, alemtuzumab has shown efficacy especially in untreated PTCL [64-67]. However, this agent can cause significant infectious and hematologic toxicities that have led to early closure of some trials [6567]. Recently, EBV-associated B-cell lymphomas have been reported complicating alemtuzumab therapy especially when 


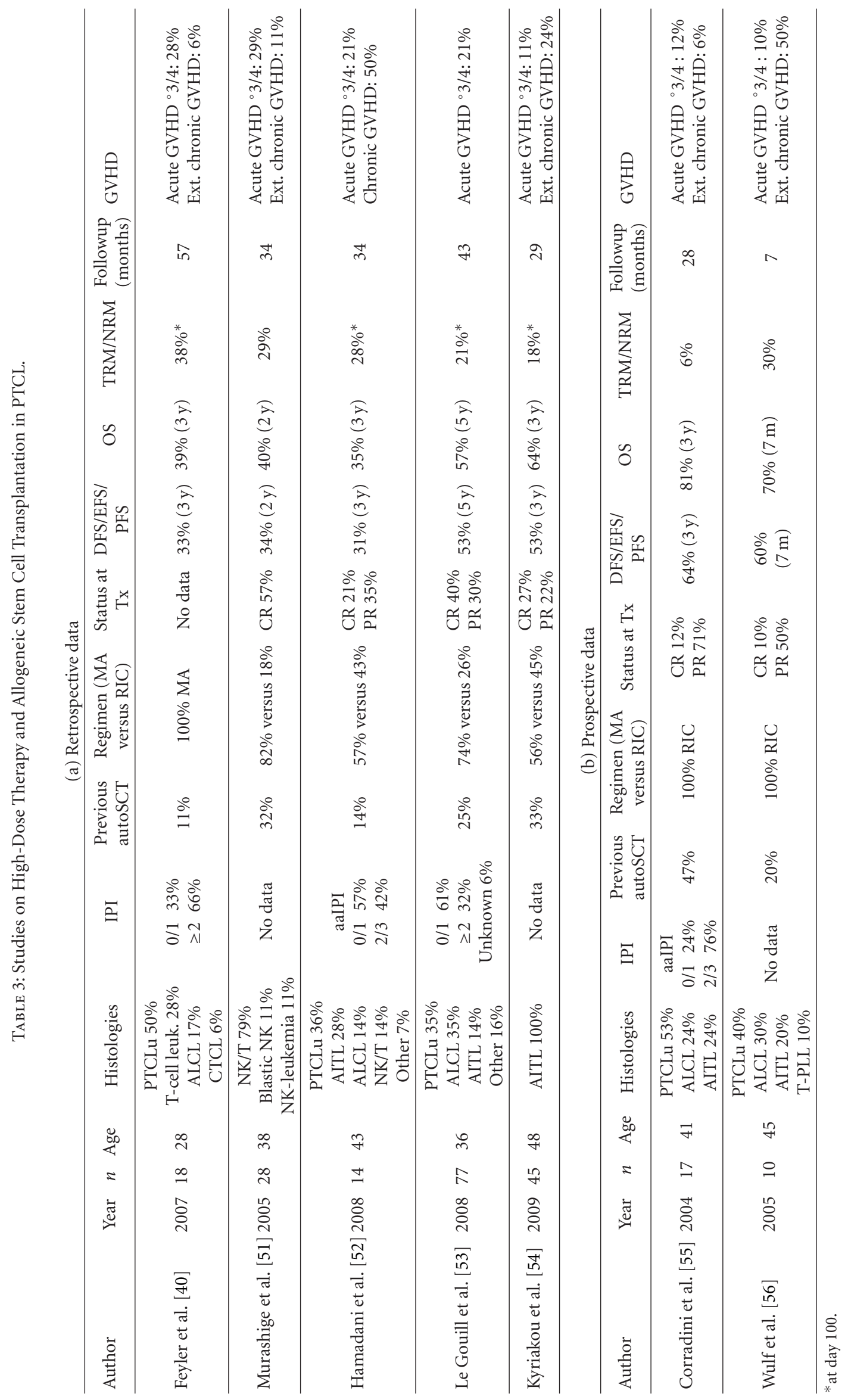


given in higher dosages $[68,69]$. To better define the role of chemoimmunotherapy in the concept of HDT-autoSCT, the Nordic Lymphoma Group is conducting a multicenter randomized trial using dose-dense chemotherapy induction with or without alemtuzumab.

Allogeneic stem cell transplantation could offer a curative option in younger patients. However, the experience with this approach is sparse and limited to relapsed and refractory PTCL. In the prospective series nonmyeloablative conditioning protocols were used with very encouraging results especially in the Italian study. Furthermore, a GVL effect could be demonstrated. Taken together, the current data support the concept of alloSCT in eligible patients with relapsing chemosensitive PTCL, especially after failing prior HDT-autoSCT.

To further investigate the role of stem cell transplantation in previously untreated PTCL, this year the DSHNHL in cooperation with other groups will initiate a prospective randomised multicenter trial comparing upfront autoSCT versus alloSCT following dose-dense induction chemotherapy.

\section{Abbreviations}

AaIPI: Age-adjusted IPI

ALCL: Anaplastic large cell lymphoma

ALK: Anaplastic lymphoma kinase

AlloSCT: Allogeneic stem cell transplantation

AITL: $\quad$ Angioimmunoblastic T-cell lymphoma

BEAC: BCNU, etoposide, cytarabin, cyclophosphamide

BEAM: BCNU, etoposide, cytarabin, melphalan

BCNU: Carmustine

BEC: Busulfan, etoposide, cyclophosphamide

CR: $\quad$ Complete remission

CVB: BCNU, etoposide, cyclophosphamide

DSF: Disease-free survival

EATL: $\quad$ Enteropathy-associated T-cell lymphoma

EFS: $\quad$ Event-free survival

Eto: $\quad$ Etoposide

IPI: International prognostic index

M: $\quad$ Months

Mel: Melphalan

NK/T: Natural killer-cell/T-cell

leukemia/lymphoma

OS: $\quad$ Overall survival

PFS: $\quad$ Progression-free survival

PR: $\quad$ Partial remission

PTCLu: Peripheral T-cell lymphoma, unspecified

Thio: Thiotepa

TRM: Treatment-related mortality

Tx: Transplantation

W: $\quad$ Weeks

Y: $\quad$ Year

CHOEP: Cyclophosphamide, vincristine, doxorubicin, etoposide, prednisone

CTCL: Cutaneous T-cell lymphoma

CVB/CBV: BCNU, etoposide, cyclophosphamide

Cy: $\quad$ Cyclophosphamide
HDT-autoSCT: High-dose therapy with autologous stem cell transplantation

HSTL: Hepatosplenic T-cell lymphoma

MCEC: Ranimustine, cyclophosphamide, etoposide, carboplatin

Mito: $\quad$ Mitoxantrone

TBI: Total body irradiation

AutoSCT: Autologous stem cell transplantation

Ext: $\quad$ Extensive

GVHD: Graft-versus-host disease

Leuk: Leukemia

MA: $\quad$ Myeloablative conditioning

NK: $\quad$ Natural killer cell

NRM: $\quad$ Nonrelapse mortality

RIC: $\quad$ Reduced intensity conditioning

T-PLL: T-cell prolymphocytic leukaemia.

\section{Conflict of Interests}

The author indicated no potential conflicts of interest.

\section{References}

[1] S. Ascani, P. L. Zinzani, F. Gherlinzoni et al., "Peripheral T-cell lymphomas. Clinico-pathologic study of 168 cases diagnosed according to the R.E.A.L. classification," Annals of Oncology, vol. 8, no. 6, pp. 583-592, 1997.

[2] J. O. Armitage, "A clinical evaluation of the International Lymphoma Study Group classification of non-Hodgkin's lymphoma," Blood, vol. 89, no. 11, pp. 3909-3918, 1997.

[3] T. Rüdiger, D. D. Weisenburger, J. R. Anderson et al., "Peripheral T-cell lymphoma (excluding anaplastic largecell lymphoma): results from the non-Hodgkin's lymphoma classification project," Annals of Oncology, vol. 13, no. 1, pp. 140-149, 2002.

[4] B. Coiffier, N. Brousse, M. Peuchmaur et al., "Peripheral T-cell lymphomas have a worse prognosis than B-cell lymphomas: a prospective study of 361 immunophenotyped patients treated with the LNH-84 regimen," Annals of Oncology, vol. 1, no. 1, pp. 45-50, 1990.

[5] J. Vose, J. Armitage, and D. Weisenburger, "International peripheral T-cell and natural killer/T-cell lymphoma study: pathology findings and clinical outcomes international T-cell lymphoma project," Journal of Clinical Oncology, vol. 26, no. 25, pp. 4124-4130, 2008.

[6] J. O. Armitage, J. M. Vose, J. Linder et al., "Clinical significance of immunophenotype in diffuse aggressive non-Hodgkin's lymphoma," Journal of Clinical Oncology, vol. 7, no. 12, pp. 1783-1790, 1989.

[7] C. Gisselbrecht, P. Gaulard, E. Lepage et al., "Prognostic significance of T-cell phenotype in aggressive non-Hodgkin's lymphomas. Groupe d'Etudes des Lymphomes de l'Adulte (GELA)," Blood, vol. 92, no. 1, pp. 76-82, 1998.

[8] A. Melnyk, A. Rodríguez, W. C. Pugh, and F. Cabannillas, "Evaluation of the revised European-American lymphoma classification confirms the clinical relevance of immunophenotype in 560 cases of aggressive non-Hodgkin's lymphoma," Blood, vol. 89, no. 12, pp. 4514-4520, 1997.

[9] S. M. Lippman, T. P. Miller, C. M. Spier, D. J. Slymen, and T. M. Grogan, "The prognostic significance of the immunotype 
in diffuse large-cell lymphoma: a comparative study of the Tcell and B-cell phenotype," Blood, vol. 72, no. 2, pp. 436-441, 1988.

[10] S. M. Ansell, T. M. Habermann, P. J. Kurtin et al., "Predictive capacity of the International Prognostic Factor Index in patients with peripheral T-cell lymphoma," Journal of Clinical Oncology, vol. 15, no. 6, pp. 2296-2301, 1997.

[11] F. Zaja, D. Russo, F. Silvestri et al., "Retrospective analysis of 23 cases with peripheral T-cell lymphoma, unspecified: clinical characteristics and outcome," Haematologica, vol. 82, no. 2, pp. 171-177, 1997.

[12] R. Sonnen, W.-P. Schmidt, H. Konrad Müller-Hermelink, and N. Schmitz, "The International Prognostic Index determines the outcome of patients with nodal mature T-cell lymphomas," British Journal of Haematology, vol. 129, no. 3, pp. 366-372, 2005.

[13] A. Gallamini, C. Stelitano, R. Calvi et al., "Peripheral T-cell lymphoma unspecified (PTCL-U): a new prognostic model from a retrospective multicentric clinical study," Blood, vol. 103, no. 7, pp. 2474-2479, 2004.

[14] P. Went, C. Agostinelli, A. Gallamini et al., "Marker expression in peripheral T-cell lymphoma: a proposed clinical-pathologic prognostic score," Journal of Clinical Oncology, vol. 24, no. 16, pp. 2472-2479, 2006.

[15] J. Rodríguez, E. Conde, A. Gutiérrez et al., “Tho adjusted International Prognostic Index and $\beta$-2-microglobulin predict the outcome after autologous stem cell transplantation in relapsing/refractory peripheral T-cell lymphoma," Haematologica, vol. 92, no. 8, pp. 1067-1074, 2007.

[16] J. Dupuis, J.-F. Emile, N. Mounier et al., "Prognostic significance of Epstein-Barr virus in nodal peripheral T-cell lymphoma, unspecified: a Groupe d'Etude des Lymphomes de l'Adulte (GELA) study," Blood, vol. 108, no. 13, pp. 4163-4169, 2006.

[17] R. D. Gascoyne, P. Aoun, D. Wu et al., "Prognostic significance of anaplastic lymphoma kinase (ALK) protein expression in adults with anaplastic large cell lymphoma," Blood, vol. 93, no. 11, pp. 3913-3921, 1999.

[18] B. Falini, S. Pileri, P. L. Zinzani et al., "ALK ${ }^{+}$lymphoma: clinico-pathological findings and outcome," Blood, vol. 93, no. 8, pp. 2697-2706, 1999.

[19] H. Q. Huang, Y. L. Peng, X. B. Lin et al., "Clinical outcomes of 106 patients with peripheral T-cell lymphoma treated by standard CHOP regimen," Ai Zheng, vol. 23, no. 11, pp. 14431447, 2004.

[20] K. Kim, W. S. Kim, C. W. Jung et al., "Clinical features of peripheral T-cell lymphomas in 78 patients diagnosed according to the Revised European-American lymphoma (REAL) classification," European Journal of Cancer, vol. 38, no. 1, pp. 75-81, 2002.

[21] A. López-Guillermo, J. Cid, A. Salar et al., "Peripheral T-cell lymphomas: initial features, natural history, and prognostic factors in a series of 174 patients diagnosed according to the R.E.A.L. Classification," Annals of Oncology, vol. 9, no. 8, pp. 849-855, 1998.

[22] J. M. Vose, C. Peterson, P. J. Bierman et al., "Comparison of high-dose therapy and autologous bone marrow transplantation for T-cell and B-cell non-Hodgkin's lymphomas," Blood, vol. 76, no. 2, pp. 424-431, 1990.

[23] R. Fanin, M. C. Ruiz de Elvira, A. Sperotto, M. Baccarani, and A. Goldstone, "Autologous stem cell transplantation for $\mathrm{T}$ and null cell CD30-positive anaplastic large cell lymphoma: analysis of 64 adult and paediatric cases reported to the European Group for Blood and Marrow Transplantation (EBMT)," Bone Marrow Transplantation, vol. 23, no. 5, pp. 437-442, 1999.

[24] J. Rodríguez, M. Munsell, S. Yazji et al., "Impact of high-dose chemotherapy on peripheral T-cell lymphomas," Journal of Clinical Oncology, vol. 19, no. 17, pp. 3766-3770, 2001.

[25] A. K. Blystad, G. Enblad, S. Kvaløy et al., "High-dose therapy with autologous stem cell transplantation in patients with peripheral T cell lymphomas," Bone Marrow Transplantation, vol. 27, no. 7, pp. 711-716, 2001.

[26] K. W. Song, P. Mollee, A. Keating, and M. Crump, "Autologous stem cell transplant for relapsed and refractory peripheral Tcell lymphoma: variable outcome according to pathological subtype," British Journal of Haematology, vol. 120, no. 6, pp. 978-985, 2003.

[27] J. Rodríguez, M. D. Caballero, A. Gutiérrez et al., "Highdose chemotherapy and autologous stem cell transplantation in peripheral T-cell lymphoma: the GEL-TAMO experience," Annals of Oncology, vol. 14, no. 12, pp. 1768-1775, 2003.

[28] J. Schetelig, S. Fetscher, A. Reichle et al., "Long-term diseasefree survival in patients with angioimmunoblastic T-cell lymphoma after high-dose chemotherapy and autologous stem cell transplantation," Haematologica, vol. 88, no. 11, pp. 1272-1278, 2003.

[29] K. W. Zamkoff, M. D. Matulis, A. C. Mehta, M. W. Beaty, R. E. Hutchison, and T. C. Gentile, "High-dose therapy and autologous stem cell transplant does not result in long-term disease-free survival in patients with reccurent chemotherapysensitive ALK-negative anaplastic large-cell lymphoma," Bone Marrow Transplantation, vol. 33, no. 6, pp. 635-638, 2004.

[30] E. Jantunen, T. Wiklund, E. Juvonen et al., "Autologous stem cell transplantation in adult patients with peripheral T-cell lymphoma: a nation-wide survey," Bone Marrow Transplantation, vol. 33, no. 4, pp. 405-410, 2004.

[31] M. Jagasia, D. Morgan, S. Goodman et al., "Histology impacts the outcome of peripheral T-cell lymphomas after high dose chemotherapy and stem cell transplant," Leukemia and Lymphoma, vol. 45, no. 11, pp. 2261-2267, 2004.

[32] T. Kewalramani, A. D. Zelenetz, J. Teruya-Feldstein et al., "Autologous transplantation for relapsed or primary refractory peripheral T-cell lymphoma," British Journal of Haematology, vol. 134, no. 2, pp. 202-207, 2006.

[33] M. K. Kim, S. Kim, S. S. Lee et al., "High-dose chemotherapy and autologous stem cell transplantation for peripheral T-cell lymphoma: complete response at transplant predicts survival," Annals of Hematology, vol. 86, no. 6, pp. 435-442, 2007.

[34] S. D. Smith, B. J. Bolwell, L. A. Rybicki et al., "Autologous hematopoietic stem cell transplantation in peripheral T-cell lymphoma using a uniform high-dose regimen," Bone Marrow Transplantation, vol. 40, no. 3, pp. 239-243, 2007.

[35] A. I. Chen, A. McMillan, R. S. Negrin, S. J. Horning, and G. G. Laport, "Long-term results of autologous hematopoietic cell transplantation for peripheral T cell lymphoma: the Stanford experience," Biology of Blood and Marrow Transplantation, vol. 14, no. 7, pp. 741-747, 2008.

[36] J. Lee, W.-Y. Au, M. J. Park et al., "Autologous hematopoietic stem cell transplantation in extranodal natural killer/T cell lymphoma: a multinational, multicenter, matched controlled study," Biology of Blood and Marrow Transplantation, vol. 14, no. 12, pp. 1356-1364, 2008.

[37] D.-H. Yang, W. S. Kim, S. J. Kim et al., "Prognostic factors and clinical outcomes of high-dose chemotherapy followed by autologous stem cell transplantation in patients with 
peripheral T cell lymphoma, unspecified: complete remission at transplantation and the prognostic index of peripheral $\mathrm{T}$ cell lymphoma are the major factors predictive of outcome," Biology of Blood and Marrow Transplantation, vol. 15, no. 1, pp. 118-125, 2009.

[38] J. Rodríguez, E. Conde, A. Gutiérrez et al., "Prolonged survival of patients with angioimmunoblastic T-cell lymphoma after high-dose chemotherapy and autologous stem cell transplantation. The GELTAMO experience," European Journal of Haematology, vol. 78, no. 4, pp. 290-296, 2007.

[39] J. Rodríguez, E. Conde, A. Gutiérrez et al., "The results of consolidation with autologous stem-cell transplantation in patients with peripheral T-cell lymphoma (PTCL) in first complete remission: the Spanish Lymphoma and Autologous Transplantation Group experience," Annals of Oncology, vol. 18, no. 4, pp. 652-657, 2007.

[40] S. Feyler, H. M. Prince, R. Pearce et al., "The role of highdose therapy and stem cell rescue in the management of T-cell malignant lymphomas: a BSBMT and ABMTRR study," Bone Marrow Transplantation, vol. 40, no. 5, pp. 443-450, 2007.

[41] C. Kyriakou, C. Canals, A. Goldstone et al., "High-dose therapy and autologous stem-cell transplantation in angioimmunoblastic lymphoma: complete remission at transplantation is the major determinant of outcome- Lymphoma Working Party of the European Group for blood and marrow transplantation," Journal of Clinical Oncology, vol. 26, no. 2, pp. 218-224, 2008.

[42] V. Prochazka, E. Faber, L. Raida et al., "Prolonged survival of patients with peripheral T-cell lymphoma after first-line intensive sequential chemotherapy with autologous stem cell transplantation," Biomedical Papers, vol. 153, no. 1, pp. 63-66, 2009.

[43] A. Numata, T. Miyamoto, Y. Ohno et al., "Long-term outcomes of autologous PBSCT for peripheral T-cell lymphoma: retrospective analysis of the experience of the Fukuoka BMT group," Bone Marrow Transplantation, vol. 45, no. 2, pp. 311$316,2010$.

[44] N. Mounier, C. Gisselbrecht, J. Brière et al., "Prognostic factors in patients with aggressive non-Hodgkin's lymphoma treated by front-line autotransplantation after complete remission: a cohort study by the Groupe d'Etude des Lymphomes de l'Adulte," Journal of Clinical Oncology, vol. 22, no. 14, pp. 2826-2834, 2004.

[45] M. Nickelsen, M. Ziepert, S. Zeynalova et al., "High-dose CHOP plus etoposide (MegaCHOEP) in T-cell lymphoma: a comparative analysis of patients treated within trials of the German High-Grade Non-Hodgkin Lymphoma Study Group (DSHNHL)," Annals of Oncology, vol. 20, no. 12, pp. 19771984, 2009.

[46] P. Corradini, C. Tarella, F. Zallio et al., "Long-term follow-up of patients with peripheral T-cell lymphomas treated up-front with high-dose chemotherapy followed by autologous stem cell transplantation," Leukemia, vol. 20, no. 9, pp. 1533-1538, 2006.

[47] J. Rodríguez, E. Conde, A. Gutiérrez et al., "Frontline autologous stem cell transplantation in high-risk peripheral T-cell lymphoma: a prospective study from the Gel-Tamo Study Group," European Journal of Haematology, vol. 79, no. 1, pp. 32-38, 2007.

[48] S. Mercadal, J. Briones, B. Xicoy et al., "Intensive chemotherapy (high-dose CHOP/ESHAP regimen) followed by autologous stem-cell transplantation in previously untreated patients with peripheral T-cell lymphoma," Annals of Oncology, vol. 19, no. 5, pp. 958-963, 2008.
[49] P. Reimer, T. Rüdiger, E. Geissinger et al., "Autologous stemcell transplantation as first-line therapy in peripheral tcell lymphomas: results of a prospective multicenter study," Journal of Clinical Oncology, vol. 27, no. 1, pp. 106-113, 2009.

[50] F. D'Amore, T. Relander, G. Lauritzsen et al., "Dosedense induction followed by autologous stem cell transplant (ASCT) as 1st line treatment in peripheral T-cell lymphomas (PTCL) - a phase II study of the Nordic Lymphoma Group (NLG)," Haematologica, vol. 94, supplement 2, p. 437, 2009.

[51] N. Murashige, M. Kami, Y. Kishi et al., "Allogeneic haematopoietic stem cell transplantation as a promising treatment for natural killer-cell neoplasms," British Journal of Haematology, vol. 130, no. 4, pp. 561-567, 2005.

[52] M. Hamadani, F. T. Awan, P. Elder et al., "Allogeneic hematopoietic stem cell transplantation for peripheral T cell lymphomas; evidence of graft-versus-T cell lymphoma effect," Biology of Blood and Marrow Transplantation, vol. 14, no. 4, pp. 480-483, 2008.

[53] S. Le Gouill, N. Milpied, A. Buzyn et al., "Graft-versuslymphoma effect for aggressive T-cell lymphomas in adults: a study by the Société Française de Greffe de Moëlle et de Thérapie Cellulaire," Journal of Clinical Oncology, vol. 26, no. 14, pp. 2264-2271, 2008.

[54] C. Kyriakou, C. Canals, J. Finke et al., "Allogeneic stem cell transplantation is able to induce long-term remissions in angioimmunoblastic T-cell lymphoma: a retrospective study from the Lymphoma Working Party of the European Group for Blood and Marrow Transplantation," Journal of Clinical Oncology, vol. 27, no. 24, pp. 3951-3958, 2009.

[55] P. Corradini, A. Dodero, F. Zallio et al., "Graft-versuslymphoma effect in relapsed peripheral T-cell non-Hodgkin's lymphomas after reduced-intensity conditioning followed by allogeneic transplantation of hematopoietic cells," Journal of Clinical Oncology, vol. 22, no. 11, pp. 2172-2176, 2004.

[56] G. G. Wulf, J. Hasenkamp, W. Jung, B. Chapuy, L. Truemper, and B. Glass, "Reduced intensity conditioning and allogeneic stem cell transplantation after salvage therapy integrating alemtuzumab for patients with relapsed peripheral T-cell nonHodgkin's lymphoma," Bone Marrow Transplantation, vol. 36, no. 3, pp. 271-273, 2005.

[57] C. Haioun, E. Lepage, C. Gisselbrecht et al., "Survival benefit of high-dose therapy in poor-risk aggressive nonHodgkin's lymphoma: final analysis of the prospective LNH87-2 protocol-a groupe d'etude des lymphomes de l'adulte study," Journal of Clinical Oncology, vol. 18, no. 16, pp. 3025-3030, 2000.

[58] N. Mounier, D. Simon, C. Haioun, P. Gaulard, C. Gisselbrecht, and I. Khouri, "Impact of high-dose chemotherapy on peripheral T-cell lymphomas," Journal of Clinical Oncology, vol. 20, no. 5, pp. 1426-1427, 2002.

[59] C. Gisselbrecht, E. Lepage, T. Molina et al., "Shortened firstline high-dose chemotherapy for patients with poor-prognosis aggressive lymphoma," Journal of Clinical Oncology, vol. 20, no. 10, pp. 2472-2479, 2002.

[60] N. Mounier, C. Gisselbrecht, J. Brière et al., "All aggressive lymphoma subtypes do not share similar outcome after frontline autotransplantation: a matched-control analysis by the Groupe d'Etude des Lymphomes de l'Adulte (GELA)," Annals of Oncology, vol. 15, no. 12, pp. 1790-1797, 2004.

[61] B. S. Sohn, I. Park, E. K. Kim et al., "Comparison of clinical outcome after autologous stem cell transplantation between patients with peripheral T-cell lymphomas and diffuse large B-cell lymphoma," Bone Marrow Transplantation, vol. 44, no. 5, pp. 287-293, 2009. 
[62] M. P. Escalón, N. S. Liu, Y. Yang et al., "Prognostic factors and treatment of patients with T-cell non-Hodgkin lymphoma: the M. D. Anderson Cancer Center experience," Cancer, vol. 103, no. 10, pp. 2091-2098, 2005.

[63] N. Schmitz, L. Trumper, M. Ziepert et al., "Treatment and prognosis of mature T-cell and NK-cell lymphoma: an analysis of patients with T-cell lymphoma treated in studies of the German High-Grade Non-Hodgkin's Lymphoma Study Group (DSHNHL)," Blood, vol. 166, no. 18, pp. 3418-3425, 2010.

[64] L. H. Trümper, K. Hohloch, M. Kloess et al., "CHOP/CHOEP14 followed by consolidation with alemtuzumab in untreated aggressive T-cell lymphomas (DSHNHL 2003-1) and toxicity of a phase II trial of the German High Grade Non-Hodgkin's Lymphoma Group DSHNHL," Journal of Clinical Oncology, vol. 24, no. 18s, p. 431: abstract 7538, 2006.

[65] J. G. Kim, S. K. Sohn, Y. S. Chae et al., "Alemtuzumab plus $\mathrm{CHOP}$ as front-line chemotherapy for patients with peripheral T-cell lymphomas: a phase II study," Cancer Chemotherapy and Pharmacology, vol. 60, no. 1, pp. 129-134, 2007.

[66] A. Gallamini, F. Zaja, C. Patti et al., "Alemtuzumab (Campath$1 \mathrm{H})$ and CHOP chemotherapy as first-line treatment of peripheral T-cell lymphoma: results of a GITIL (Gruppo Italiano Terapie Innovative nei Linfomi) prospective multicenter trial," Blood, vol. 110, no. 7, pp. 2316-2323, 2007.

[67] E. Weidmann, G. Hess, K. U. Chow et al., "A phase II study of alemtuzumab, fludarabine, cyclophosphamide, and doxorubicin (Campath-FCD) in peripheral T-cell lymphomas," Leukemia and Lymphoma, vol. 51, no. 3, pp. 447-455, 2010.

[68] K. C. Weisel, E. Weidmann, I. Anagnostopoulos, L. Kanz, A. Pezzutto, and M. Subklewe, "Epstein-Barr virus-associated B-cell lymphoma secondary to FCD-C therapy in patients with peripheral T-cell lymphoma," International Journal of Hematology, vol. 88, no. 4, pp. 434-440, 2008.

[69] H. C. Kluin-Nelemans, J. L. Coenen, J. E. Boers, G. W. Van Imhoff, and S. Rosati, "EBV-positive immunodeficiency lymphoma after alemtuzumab-CHOP therapy for peripheral T-cell lymphoma," Blood, vol. 112, no. 4, pp. 1039-1041, 2008. 


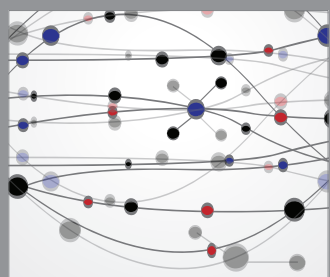

The Scientific World Journal
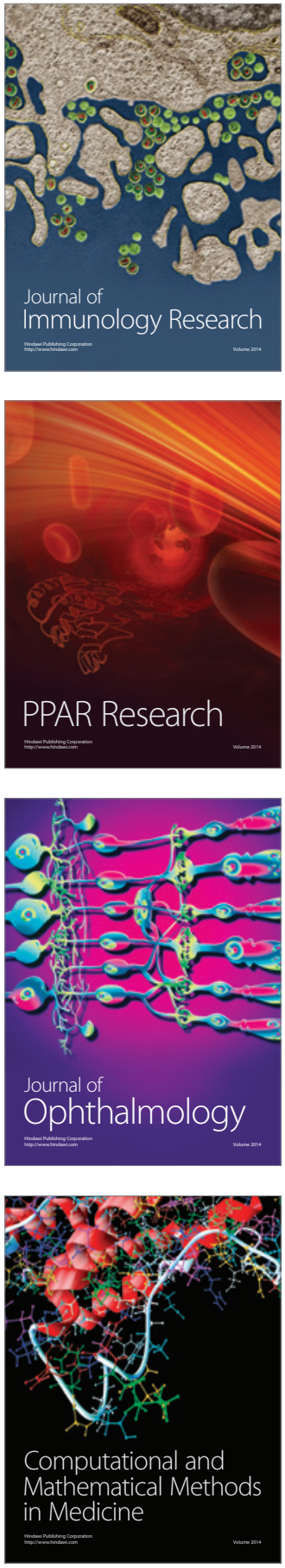

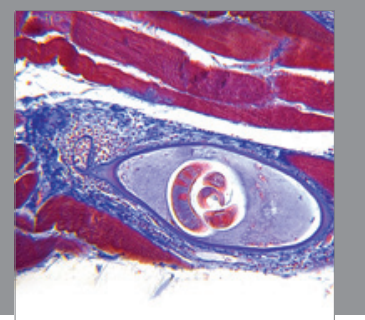

Gastroenterology

Research and Practice
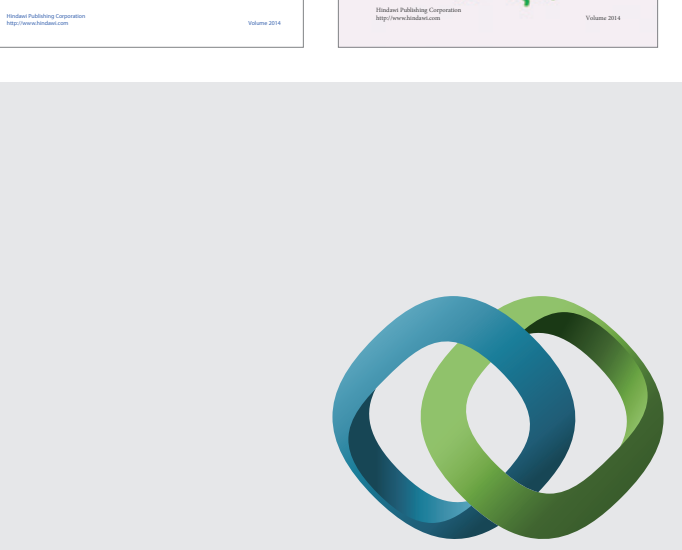

\section{Hindawi}

Submit your manuscripts at

http://www.hindawi.com
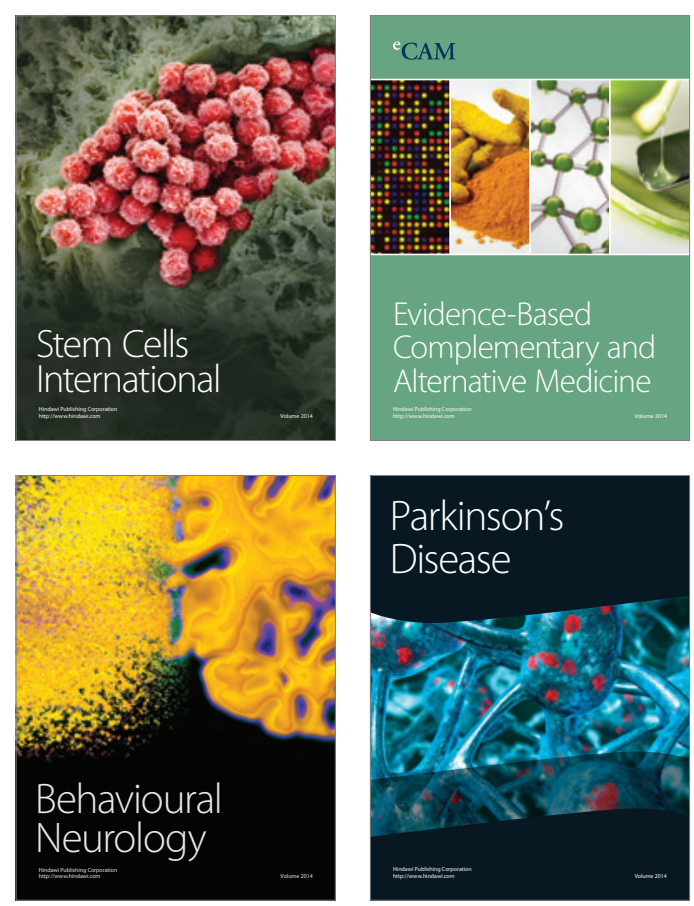

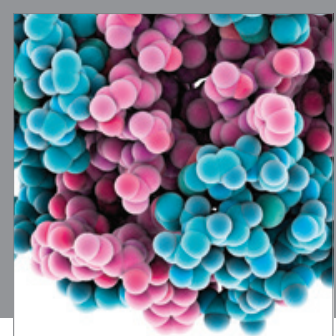

Journal of
Diabetes Research

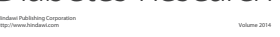

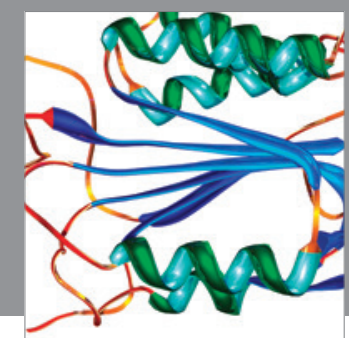

Disease Markers
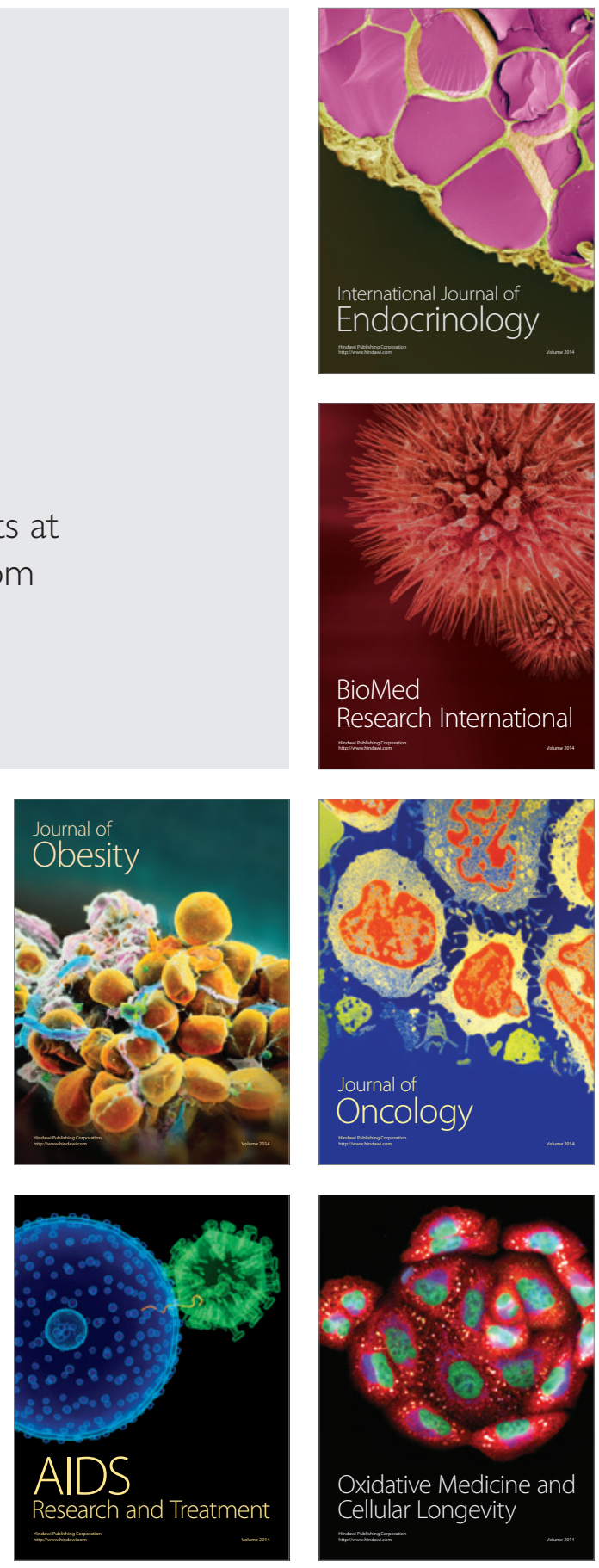